\title{
Role of Vanadyl Oxygen in Understanding Metallic Behavior of $\mathrm{V}_{2} \mathrm{O}_{5}(001)$ Nanorods
}

\author{
Raktima Basu, ${ }^{*}$ Arun K. Prasad, Sandip Dhara, ${ }^{*}$ and A. Das
}

Nanomaterials and Sensors Section, Surface and Nanoscience Division, Indira Gandhi Centre for Atomic Research, Homi Bhabha National Institute, Kalpakkam-603 102, India

\section{Corresponding Authors}

*Email Address: raktimabasu14@gmail.com; dhara@igcar.gov.in

Telephone: +914427480015

\section{Abstract}

Vanadium pentoxide $\left(\mathrm{V}_{2} \mathrm{O}_{5}\right)$, the most stable member of vanadium oxide family, exhibits interesting semiconductor to metal transition in the temperature range of 530-560K. The metallic behavior originates because of the reduction of $\mathrm{V}_{2} \mathrm{O}_{5}$ through oxygen vacancies. In the present report, $\mathrm{V}_{2} \mathrm{O}_{5}$ nanorods in the orthorhombic phase with crystal orientation of $(001)$, are grown using vapor transport process. Among three non-equivalent oxygen atoms in a $\mathrm{VO}_{5}$ pyramidal formula unit in $\mathrm{V}_{2} \mathrm{O}_{5}$ structure, the role of terminal vanadyl oxygen $\left(\mathrm{O}_{\mathrm{I}}\right)$ in the formation of metallic phase above the transition temperature is established from the temperature dependent Raman spectroscopic studies. The origin of the metallic behavior of $\mathrm{V}_{2} \mathrm{O}_{5}$ is also understood due to the breakdown of $p d \pi$ bond between $\mathrm{O}_{\mathrm{I}}$ and nearest $\mathrm{V}$ atom instigated by the formation of vanadyl $\mathrm{O}_{\mathrm{I}}$ vacancy, confirmed from the downward shift of the bottom most split-off conduction bands in the material with increasing temperature. 


\section{Introduction}

One dimensional transition metal oxides exhibit unique structure-property relationships which help in developing new electronic and photonic devices. ${ }^{1,2}$ Vanadium is a transition metal ([Ar] $\left.3 d^{3} 4 s^{2}\right)$ with multiple oxidation states leading to various stoichiometric oxides. Vanadium pentoxide $\left(\mathrm{V}_{2} \mathrm{O}_{5}\right)$, which is essentially a semiconductor at room temperature, is the most stable form among them. Although, most of vanadium oxides such as $\mathrm{VO}_{2}, \mathrm{~V}_{2} \mathrm{O}_{3}, \mathrm{~V}_{6} \mathrm{O}_{13}$ exhibit metal to insulator transitions (MITs) as a function of temperature, in case of $\mathrm{V}_{2} \mathrm{O}_{5}$ it is quite contentious to use the term 'MIT' ${ }^{3}$ However, there are few reports about transition to metallic phase of $\mathrm{V}_{2} \mathrm{O}_{5}$ films around 530 to $553 \mathrm{~K}$ and surface metallicity of (001) facet around 340 to 400K. ${ }^{4-6}$ The MIT is also reported to be reversible. ${ }^{6}$ The metallic behavior makes $\mathrm{V}_{2} \mathrm{O}_{5}$ applicable as gas sensors, ${ }^{7,8}$ thermochromic devices, ${ }^{9,10}$ optical and electrical switches ${ }^{11}$ around the transition temperature.

The origin of the metallic behavior, however, is still not fully understood. The metallic transition was reported because of the reduction of $\mathrm{V}_{2} \mathrm{O}_{5}$ to other lower ordered stoichiometric or non-stoichiometric oxides without any structural change. ${ }^{5,12}$ In the structure of $\mathrm{V}_{2} \mathrm{O}_{5}$ there are three differently coordinated $\mathrm{O}$ atoms, namely, $\mathrm{O}_{\mathrm{I}}$ (vanadyl), $\mathrm{O}_{\mathrm{II}}$ (bridging), and $\mathrm{O}_{\mathrm{III}}$ (chain) (schematic in the supplementary information Figure S1). ${ }^{13}$ There is also a dispute in the identification of the oxygen responsible for the reduction as all three $\mathrm{O}_{\mathrm{I}},{ }^{6,14} \mathrm{O}_{\mathrm{II}},{ }^{15}$ and $\mathrm{O}_{\mathrm{III}}{ }^{16}$ are suggested to be the eligible candidates. A structural phase transition from $\alpha-\mathrm{V}_{2} \mathrm{O}_{5}$ to metastable $\gamma^{\prime}-\mathrm{V}_{2} \mathrm{O}_{5},{ }^{17}$ however, is also proposed with the increase in temperature to explain metallicity above the trasition temperature, as $\gamma^{\prime}-\mathrm{V}_{2} \mathrm{O}_{5}$ resembles conductive Wadsley phase of $\mathrm{V}_{4} \mathrm{O}_{9} .{ }^{18}$

In the present study, we report semiconductor to metal transition of (001) oriented $\mathrm{V}_{2} \mathrm{O}_{5}$ nanorods, grown using vapour transport process. A transition from semiconducting to metallic 
behavior was recorded in the temperature dependent I-V measurement. The reversible temperature dependent Raman spectra were analyzed for the allowed vibrational modes of semiconducting and metallic $\mathrm{V}_{2} \mathrm{O}_{5}$ phases to understand the origin of the transition. The change in electronic band structure after the reduction of $\mathrm{V}_{2} \mathrm{O}_{5}$, prompting the metallicity in the sample, is discussed using temperature dependent Ultraviolet-Visible (UV-Vis) absorption spectroscopic studies and thermal activation energy calculations.

\section{Experimental details}

$\mathrm{V}_{2} \mathrm{O}_{5}$ nanorods were synthesized by vapor transport process using bulk $\mathrm{VO}_{2}$ powder (Sigma-Aldrich, 99\%) as source, placed in a high pure (99.99\%) alumina boat at the center of the quartz tube reaction chamber, and flowing $20 \mathrm{sccm}$ of $\operatorname{Ar}(99.9 \%)$ as carrier gas. Samples were grown on $\mathrm{SiO}_{2} / \mathrm{Si}(100)$ using $\mathrm{Au}$ thin film $(2 \mathrm{~nm})$ as catalyst. The substrate was kept $5 \mathrm{~cm}$ away from the source normal to the stream of Ar. The synthesis was carried out at $1173 \mathrm{~K}$ for $2 \mathrm{~h}$.

Morphological analysis of the pristine sample was studied using a field emission scanning electron microscope (FESEM, SUPRA 55 Zeiss). The crystallographic studies were performed with the help of glancing incidence x-ray diffractometer (GIXRD; Bruker D8) using a $\mathrm{Cu} \mathrm{K}_{\alpha}$ radiation source $(\lambda=1.5406 \AA)$ with a glancing angle $(\theta)$ of $0.5^{\circ}$ in the $\theta-2 \theta$ mode. $\mathrm{A}$ micro-Raman spectrometer (inVia, Renishaw, UK), in the back scattering configuration, was used for $\mathrm{Ar}^{+}$laser $(514.5 \mathrm{~nm})$ excitation with a diffraction gratings of 1800 gr. $\mathrm{mm}^{-1}$ for monochromatization and a thermoelectric cooled charged coupled device (CCD) detector to study the vibrational modes. Electrical measurements were carried out by two Au coated contact tips. The activation energy $\mathrm{E}_{a}$ was calculated from the slope of $\ln (\mathrm{R})$ vs. $(1 / \mathrm{T})$ plot, using the

formula $R=R_{0} \exp \left(-E_{a} / \mathrm{K}_{\mathrm{B}} \mathrm{T}\right)$ where $K_{\mathrm{B}}$ is the Boltzmann constant, $R_{0}$ is the resistance at temperature $\mathrm{T}=0 \mathrm{~K}$. Absorption spectra were recorded using an $\mathrm{UV}$-Vis absorption spectrometer 
(Avantes) in the range of 200 to $700 \mathrm{~nm}$. The Tauc's plots of the as-grown material, were drown using $(\alpha h v)^{1 / n}$ vs. $h v$ with $n=2$ for indirect band gap semiconductor (absorption co-efficient, $\alpha$; Planck's constant, $h$; frequency, $v$ ). Temperature dependent spectroscopic studies and electrical measurements were performed in the Linkam (THMS600) stage.

\section{Results and discussions}

The typical field FESEM image (Figure 1(a)) of as-grown sample shows rod like structure with an average diameter of 200-300 nm. The inset in figure 1(a) shows high magnification image of a typical single nanorod.

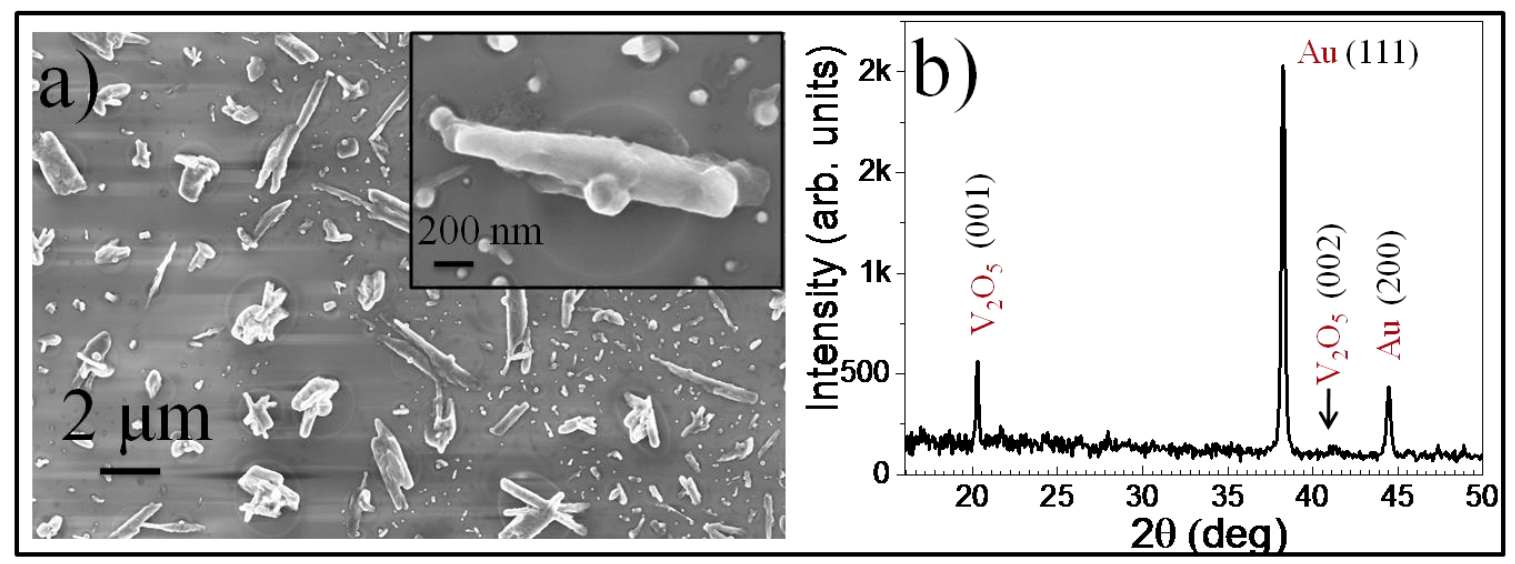

Figure 1. (a) FESEM image of as-grown nanorods. Inset shows a high resolution image of a typical nanorod (b) GIXRD spectrum of as-grown sample indicating crystalline planes corresponding to phases present.

The phase of the as-grown material was analyzed by GIXRD in the studies. Figure 1(b) shows the GIXRD data with peaks corresponding to the $(h k l)$ planes of (001) and (002), confirming pure $\mathrm{V}_{2} \mathrm{O}_{5}$ phase (ICCD 00-041-1426) with unit cell dimensions $a=11.51 \AA, b=$ $3.56 \AA$ and $c=4.37 \AA$ grown with (001) crystalline orientation..$^{13}$ As we have used Au as catalyst 
for the nanostructure growth, the GIXRD spectrum shows peaks corresponding to (111) and (200) planes for $\mathrm{Au}(\mathrm{ICCD} 00-004-0784)$ also.

Group theoretical analysis predicts twenty one Raman active modes for $\mathrm{V}_{2} \mathrm{O}_{5}$ at $\Gamma$ point, $7 A_{\mathrm{g}}+7 B_{2 \mathrm{~g}}+3 B_{1 \mathrm{~g}}+4 B_{3 \mathrm{~g} .}{ }^{19}$ However, we observed eleven Raman modes for as-grown nanorods (Figure 2), which match with the reported data for $\mathrm{V}_{2} \mathrm{O}_{5} \cdot{ }^{19,20}$

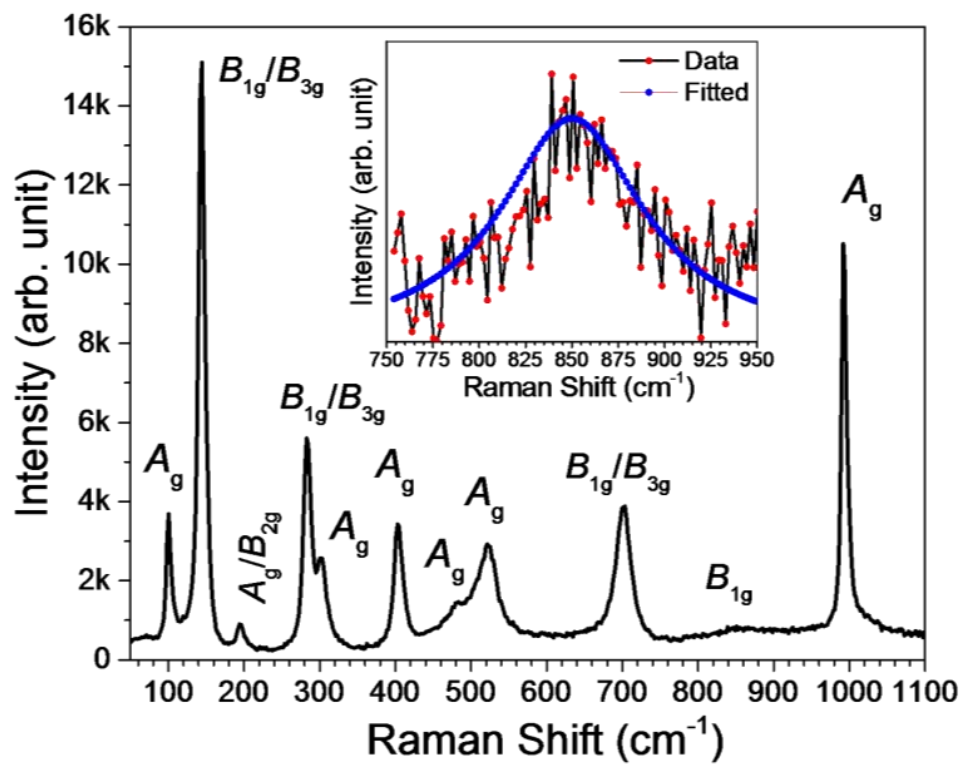

Figure 2. Raman spectrum of the as grown $\mathrm{V}_{2} \mathrm{O}_{5}$ nanorods with excitation of $514.5 \mathrm{~nm}$ at room temperature. The inset shows fitted peak at $850 \mathrm{~cm}^{-1}$ corresponding to $B_{1 \mathrm{~g}}$ mode.

The Raman peaks at $102\left(A_{\mathrm{g}}\right), 144$ (either $B_{1 \mathrm{~g}}$ or $\left.B_{3 \mathrm{~g}} ; B_{1 \mathrm{~g}} / B_{3 \mathrm{~g}}\right), 195\left(A_{\mathrm{g}} / B_{2 \mathrm{~g}}\right), 283\left(B_{1 \mathrm{~g}} / B_{3 \mathrm{~g}}\right)$, $301\left(A_{\mathrm{g}}\right), 403\left(A_{\mathrm{g}}\right), 483\left(A_{\mathrm{g}}\right), 523\left(A_{\mathrm{g}}\right), 701\left(B_{1 \mathrm{~g}} / B_{3 \mathrm{~g}}\right), 850\left(B_{1 \mathrm{~g}}\right)$ and $993\left(A_{\mathrm{g}}\right) \mathrm{cm}^{-1}$ confirm the presence of pure $\mathrm{V}_{2} \mathrm{O}_{5}$ phase. ${ }^{19}$ Orthorhombic $\mathrm{V}_{2} \mathrm{O}_{5}$ is made of distorted $\mathrm{VO}_{5}$ pyramids sharing edges and corners having space group $P_{m m n}\left(D_{2 h}^{13}\right) .{ }^{21}$ The eleven observed Raman peaks can be assigned as follows. The highest frequency peak at $993 \mathrm{~cm}^{-1}$ appears due to the stretching vibrational mode of $\mathrm{V}-\mathrm{O}_{\mathrm{I}}$ bond along $Z$ direction (detail structure may be referred to supplementary information Figure S1). The peak at $850 \mathrm{~cm}^{-1}$ (inset of Figure 2), observed 
experimentally for the first time, is predicted to originate because of antiphase stretching mode of $\mathrm{V}$-O II bonds corresponding to the displacement of $\mathrm{O}_{\text {II }}$ atoms along $X$ direction. ${ }^{19}$ The very weak intensity of the mode is due to pseudo-centrosymmetric nature of $\mathrm{V}-\mathrm{O}$ II- $\mathrm{V}$ bond. ${ }^{20}$ Displacement of $\mathrm{O}_{\mathrm{III}}$ atoms in $Y$ and $X$ directions generates Raman modes at $701 \mathrm{~cm}^{-1}\left(\mathrm{~V}-\mathrm{O}_{\mathrm{III}}-\mathrm{V}\right.$ antiphase stretching mode) and $523 \mathrm{~cm}^{-1}$ ( $d_{4}$ stretching vibration), respectively. The V-O II- $\mathrm{V}$ bending deformation along $Z$ direction ( $c$ axis) gives rise to Raman mode at $483 \mathrm{~cm}^{-1}$. Modes at 403 and $283 \mathrm{~cm}^{-1}$ can be attributed to oscillation of $\mathrm{O}_{\mathrm{I}}$ atoms along $X$ and $Y$ axes, respectively. One the other hand, displacement of $\mathrm{O}_{\text {II }}$ atoms along $Z$ axis gives rise to Raman peak at $301 \mathrm{~cm}^{-1}$. The low frequency modes at 195,144 and $102 \mathrm{~cm}^{-1}$ correspond to the $X, Y$ and $Z$ displacements of the whole chain involving shear and rotations of the ladder like V-O III bonds. ${ }^{20,22}$ The high intensity of $144 \mathrm{~cm}^{-1}$ peak indicates the long range order of V-O layers in the $X Y$ plane. ${ }^{20}$

$\mathrm{V}_{2} \mathrm{O}_{5}$ is an indirect band gap semiconductor, with a gap value of about $2 \mathrm{eV} \cdot{ }^{23,24}$ Presence of two localized narrow split-off bands with a gap of $\sim 0.7 \mathrm{eV}$ at the bottom of conduction band is considered as the most interesting feature of its electronic band structure. ${ }^{24}$ The upper split-off band is separated from the main conduction band by an additional gap of 0.35 to $0.5 \mathrm{eV} .^{23-25}$ However, $\mathrm{V}_{2} \mathrm{O}_{5}$ shows metallic behavior above the transition temperature. 


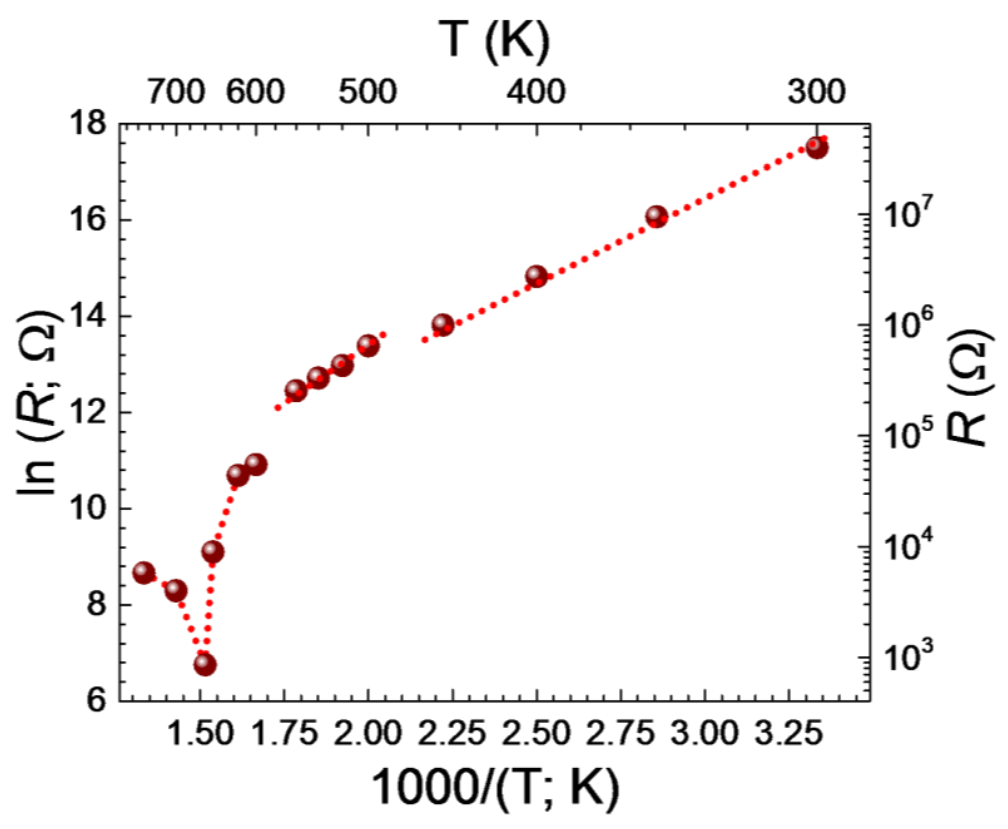

Figure 3. Change in the resistance with temperature in an ensemble of $\mathrm{V}_{2} \mathrm{O}_{5}$ nanorods

The semi log plot of resistance $(R) \quad v s . \mathrm{T}^{-1}$ shows (Figure 3) that resistance decreases exponentially up to $450 \mathrm{~K}$ with increasing temperature, indicating a semiconducting behavior leading to an activation energy of $0.29 \pm 0.01 \mathrm{eV}$, which is slightly higher than the previously reported value $(0.26 \mathrm{eV})$ for single crystalline $\mathrm{V}_{2} \mathrm{O}_{5}$, measured in the temperature range of 200$270 \mathrm{~K} .{ }^{26}$ The most possible reason for this low value of activation energy is due to the transition of electrons from localized split-off bands to main conduction band. In the temperature range of $500-550 \mathrm{~K}$, the slope of the plot is increased with an activation energy of $0.4 \pm 0.01 \mathrm{eV}$, which indicates the downward shift of split-off bands with increasing temperature. Above 550K, it starts decreasing rapidly disobeying the semiconducting nature, and the plot shows metallic behavior of increasing resistance with increase in the temperature above $650 \mathrm{~K}$. As discussed earlier, the cause of the metallic behavior is still under debate. ${ }^{5,6,15-17}$ The proposed metallic phase of metastable $\gamma^{\prime}-\mathrm{V}_{2} \mathrm{O}_{5}$ in the structural phase transition model, ${ }^{17}$ is reported to convert to a stable semiconducting $\alpha-\mathrm{V}_{2} \mathrm{O}_{5}$ phase above $613 \mathrm{~K} \cdot{ }^{27}$ In the present study, however, the 
temperature dependent electrical measurement shows (Figure 3) that the metallic character of the grown nanorods sustains above $650 \mathrm{~K}$, which contradicts the formation of $\gamma^{\prime}-\mathrm{V}_{2} \mathrm{O}_{5}$. Hence the reduction of $\mathrm{V}_{2} \mathrm{O}_{5}$ though $\mathrm{O}$ vacancy with no structural change is likely in producing the metallic phase above the transition temperature. ${ }^{5}$ However, the role of specific $\mathrm{O}$ (supplementary information Figure S1) is still not clear in producing the metallic phase.

A temperature dependent Raman spectroscopic study (Figure 4(a)) was conducted to address the role of specific $\mathrm{O}$ in producing the metallic phase.

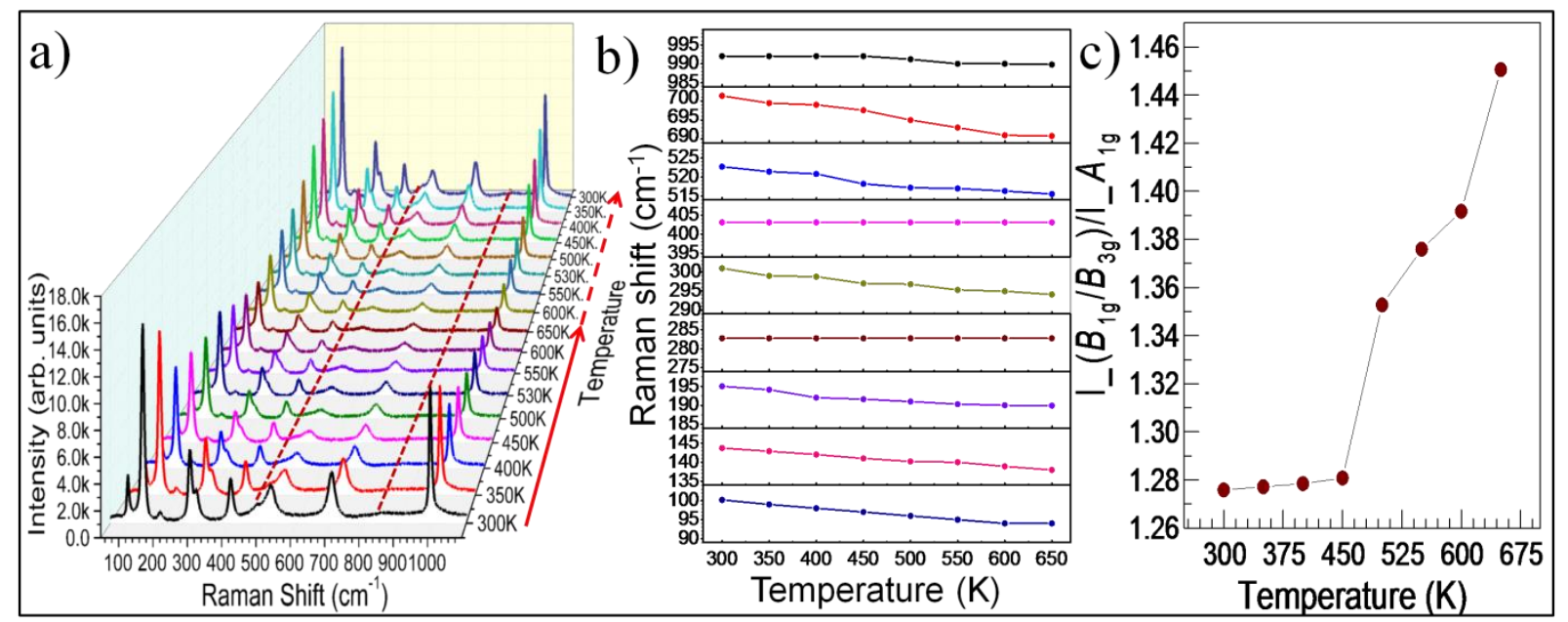

Figure 4. (a) Raman spectra of $\mathrm{V}_{2} \mathrm{O}_{5}$ nanorods with increasing (denoted by solid arrow) and decreasing (denoted by dashed arrow) temperature in the range of 300 to $650 \mathrm{~K}$ (b) Change in vibrational frequency with temperature for each Raman mode and (c) Temperature dependence of the intensity ratio of the highest intense peak at $144 \mathrm{~cm}^{-1}\left(\mathrm{I} \_\left(B_{1 \mathrm{~g}} / B_{3 \mathrm{~g}}\right)\right)$ with the peak at $993 \mathrm{~cm}^{-1}\left(\mathrm{I} \_A_{1 \mathrm{~g}}\right)$.

In temperature dependent Raman study, the modes at 483 and $850 \mathrm{~cm}^{-1}$ are observed to disappear completely above the transition temperature of $530 \mathrm{~K}$ and reappear again at the same temperature while cooling down. Moreover, a softening for all Raman modes was recorded with the increase in temperature except for the mode frequencies at 283, 403 and $993 \mathrm{~cm}^{-1}$. Temperature 
dependence (increasing) of frequencies for all the observed Raman modes is shown in figure 4(b). The peak positions of the Raman modes, except for the three above mentioned modes, are red shifted by an amount of 7 to $13 \mathrm{~cm}^{-1}$ in the temperature range from 300 to $650 \mathrm{~K}$. The intensity of the peak centered at $993 \mathrm{~cm}^{-1}$ is observed to decrease rapidly with the increase in temperature and regain almost its original intensity after cooling back to room temperature. The intensity ratio of the highest intense $144 \mathrm{~cm}^{-1}\left(B_{1 \mathrm{~g}} / B_{3 \mathrm{~g}}\right)$ Raman mode with $993 \mathrm{~cm}^{-1}\left(A_{1 \mathrm{~g}}\right)$ mode with increasing temperature is shown in figure $4(\mathrm{c})$. The intensity ratio (I__ $\left.\left(B_{1 \mathrm{~g}} / B_{3 \mathrm{~g}}\right) / \mathrm{I}_{-} A_{1 \mathrm{~g}}\right)$ increases rapidly above the temperature $450 \mathrm{~K}$ indicating a significant decrease in the intensity of $A_{1 \mathrm{~g}}$ mode centered at $993 \mathrm{~cm}^{-1}$ as compared to that of $B_{1 \mathrm{~g}} / B_{3 \mathrm{~g}}$ mode of $144 \mathrm{~cm}^{-1}$ around the transition temperature of $530 \mathrm{~K}$. The drastic fall in intensity of the $A_{1 \mathrm{~g}}$ mode, which is responsible for the vibration of vanadyl $\mathrm{O}_{\mathrm{I}}$ atoms along $c$-axis alone, signifies the possible loss of $\mathrm{O}_{\mathrm{I}}$ atoms from the structure around the transition temperature. It may also be noted that the $B_{1 \mathrm{~g}} / B_{3 \mathrm{~g}}$ mode frequency at $144 \mathrm{~cm}^{-1}$ is independent of the motion of $\mathrm{O}_{\mathrm{I}}$, so our inference about the role of $\mathrm{O}_{\mathrm{I}}$ influencing the intensity of $A_{1 \mathrm{~g}}$ mode at $993 \mathrm{~cm}^{-1}$ is mutually exclusive. Moreover, it is reported that the vanadyl $\mathrm{O}_{\mathrm{I}}$ is more prone to reduction, as the vacancy formation energy is lower for $\mathrm{O}_{\mathrm{I}}$ atoms than the other two coordinated oxygen atoms ( $\mathrm{O}_{\text {II }}$ and $\mathrm{O}_{\text {III }}$ ) in $\mathrm{V}_{2} \mathrm{O}_{5}(001)$ oriented surface. ${ }^{28,29}$ The modes at 483 and $850 \mathrm{~cm}^{-1}$, arising due to $\mathrm{V}-\mathrm{O}_{\mathrm{II}} \mathrm{V}$ bending and stretching vibrations, respectively, disappeared above the transition temperature. It may be due to the

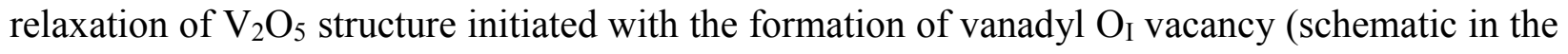
supplementary information Figure S2). If one of the vanadyl oxygen atoms are removed from the surface, the $\mathrm{V}$ atom in its near vicinity projects inward for relaxation and the next right vanadyl oxygen relax upward to make a stiffer interlayer bond with increased bond length (1.78 $\AA$ ). Moreover, the $\mathrm{V}-\mathrm{O}_{\mathrm{II}}-\mathrm{V}$ bond angle is also reported to increase to $178^{\circ}$ leading to almost a linear 
bond.$^{28}$ So, the disappearance of the modes at 483 and $850 \mathrm{~cm}^{-1}$ is in quite good agreement with the relaxation conditions. The absence of phonon softening with temperature for the Raman modes at 283, 403 and $993 \mathrm{~cm}^{-1}$, which originates due to the $Y, X$ and $Z$ vibration of $\mathrm{O}_{\mathrm{I}}$ atoms, respectively, may also be attributed to the structural relaxation as the $\mathrm{V}$-O $\mathrm{O}$ bonds become stiffer between the layers after the relaxation. The reversibility of the Raman modes with temperature can be explained by the excellent catalytic behavior of $\mathrm{V}_{2} \mathrm{O}_{5}$. Structural phase transition to $\gamma^{\prime}$ $\mathrm{V}_{2} \mathrm{O}_{5}$ is further ruled out with the absence of Raman mode at $602 \mathrm{~cm}^{-1},{ }^{30}$ in the studied temperature range of 300-650K.

To understand the origin of metallicity in $\mathrm{V}_{2} \mathrm{O}_{5}$, temperature dependent UV-Vis absorption of the as-grown $\mathrm{V}_{2} \mathrm{O}_{5}$ nanorods was studied. $\mathrm{V}_{2} \mathrm{O}_{5}$ is a semiconductor with an indirect band gap of $\sim 2 \mathrm{eV}$ corresponding to a transition from $R$ to $\Gamma$ point in the first Brillouin zone. ${ }^{23,24}$ Two split-off bands with narrow bandwidth $(0.45$ to $0.75 \mathrm{eV})$ below the conduction band at $\Gamma$ point are also reported. ${ }^{24,25}$ Vanadyl $\mathrm{O}_{\mathrm{I}}$ plays an important role in creating these split-off conduction bands. $^{31,32}$ The Tauc's plot of the as-grown material, using $(\alpha h v)^{1 / 2}$ vs. $h v$ for indirect band gap semiconductor (absorption co-efficient, $\alpha$; Planck's constant, $h$; frequency, $v$ ), at different temperatures ranging from 300 to $650 \mathrm{~K}$ are shown in figure 5 . 


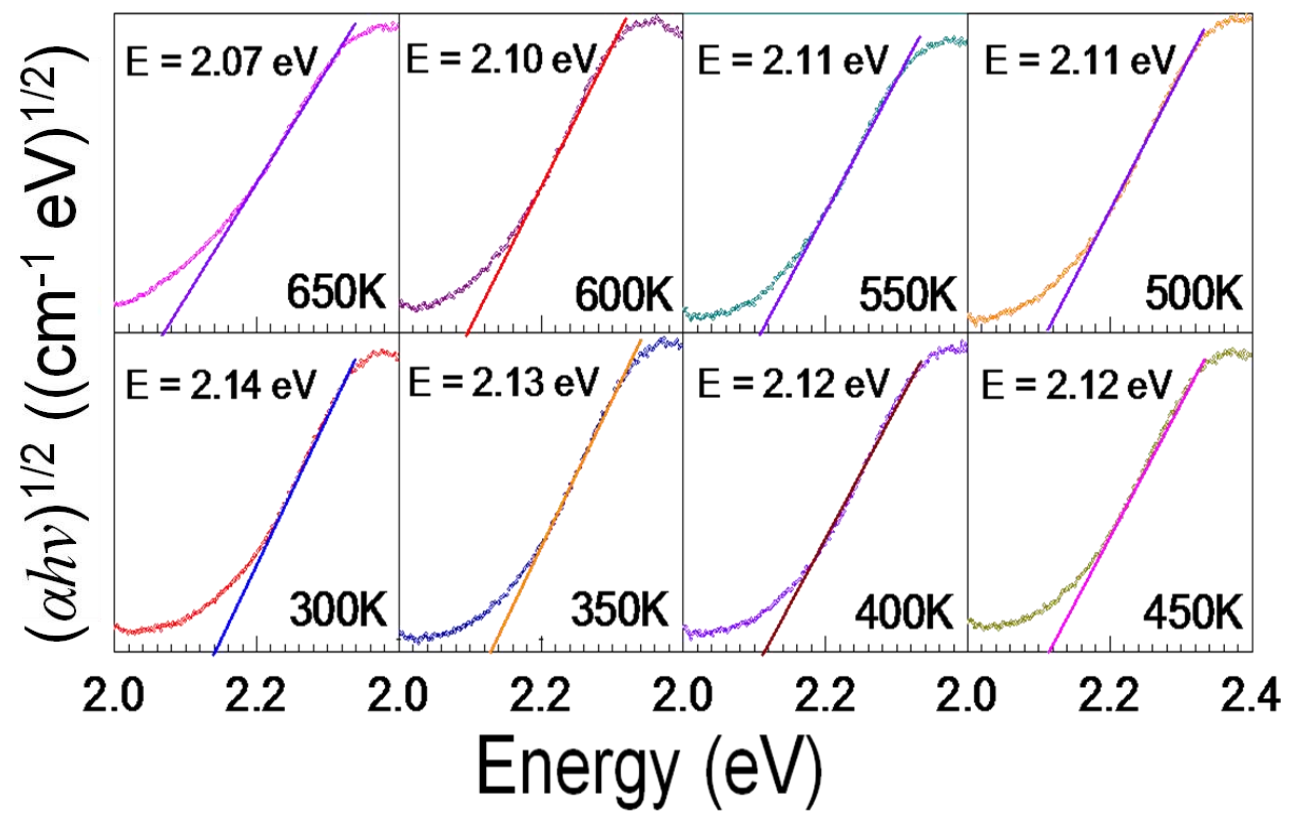

Figure 5. Tauc's plot of indirect band gap $\mathrm{V}_{2} \mathrm{O}_{5}$ nanorods using UV-Visible spectra at different temperatures. The slopes are drawn to determine the band gap value, as inscribed in the insets for the plots at different temperatures.

An indirect band gap of $2.14 \mathrm{eV}$, which matches with the previously reported value of $2.1 \mathrm{eV},^{33}$ was recorded at $300 \mathrm{~K}$. The band gap decreases with increase in temperature and is measured to attain a value of $2.07 \mathrm{eV}$ at $650 \mathrm{~K}$. The decrease in band gap by an amount of $70 \mathrm{meV}$ indicates downward shift of the split-off bands with increase in temperature, as also inferred from the thermal activation energy analysis (Figure 3). Inspired by the vanadyl $\mathrm{O}_{\mathrm{I}}$ vacancy, the split-off conduction bands are reported to approach deeper down from the conduction band at $\Gamma$ point due to the breakdown of $p d \pi$ bond between $\mathrm{O}_{\mathrm{I}}$ and nearest $\mathrm{V}$ atom. ${ }^{14,31,32}$ Reduction of an oxygen atom donates two electrons back to the structure. The breakdown of $p d \pi$ bond between $\mathrm{O}_{\mathrm{I}}$ and nearest $\mathrm{V}$ atom results in delocalization of electrons towards neighboring $\mathrm{V}$ cation by occupying the partially filled V $3 d$ states in the conduction band, ${ }^{34}$ leading to the increase in the number of carriers in the conduction band. The increased number of carriers in the conduction band may be 
responsible for the decrease in resistance above the transition temperature and the observed metallic behavior. Thus, the decrease in band gap with increasing temperature supports our assumption of vanadyl $\mathrm{O}_{\mathrm{I}}$ vacancy from the $\mathrm{V}_{2} \mathrm{O}_{5}$ structure above the transition temperature.

\section{Conclusion}

In conclusion, orthorhombic $\mathrm{V}_{2} \mathrm{O}_{5}(001)$ nanorods were synthesized by vapor transport method. Temperature dependent electrical properties showed a transition of semiconducting to metallic behavior at temperature of $550 \mathrm{~K}$. Phonon softening behavior in the temperature dependent Raman spectra indicated loss of vanadyl oxygen $\left(\mathrm{O}_{\mathrm{I}}\right)$ as the most possible reason for the observation of the metallic $\mathrm{V}_{2} \mathrm{O}_{5}$ phase above the transition temperature. Reduction of the band gap with increasing temperature, as observed in the Tauc's plot and thermal activation energy calculations, implies the downward movement of split-off bands from the conduction band. The downward shift of split-off bands with increase in temperature is due to breakdown of $p d \pi$ bond between $\mathrm{O}_{\mathrm{I}}$ and nearest $\mathrm{V}$ atom, inspired by the formation of vanadyl $\mathrm{O}_{\mathrm{I}}$ vacancy. The breakdown of $p d \pi$ bonds helps in accumulating electrons towards neighboring $\mathrm{V}$ atom to occupy the partially filled $\mathrm{V} 3 d$ bands, leading to the increase in the number of carriers in conduction band, which is finally made responsible for the decrease in the resistance and the observed metallic behavior, for the first time.

\section{AUTHOR INFORMATION:}

*Email Address: raktimabasu14@gmail.com; dhara@igcar.gov.in

\section{ACKNOWLEDGMENT}

One of us (RB) thanks DAE, India for financial support. We also acknowledge D. N. Sunitha, S. R. Polaki and A. Pasta of SND, IGCAR for their help in GIXRD, FESEM and electrical studies, respectively. 


\section{REFERENCES}

(1) Poizot, P.; Laruelle, S.; Grugeon, S.; Dupont, L.; Tarascon, J-M. Nano-Sized Transition Metal Oxides as Negative-Electrode Materials for Lithium-Ion Batteries. Nature 2000, 407, 496-499.

(2) Rao, C.N. R. Transition Metal Oxides. Annu. Rev. Phys. Chem. 1989, 40, 291-326.

(3) Pergament, A.; Stefanovich, G.; Andreev, V. Comment on "Metal-Insulator Transition without Structural Phase Transition in $\mathrm{V}_{2} \mathrm{O}_{5}$ Film” [Appl. Phys. Lett. 98, 131907 (2011)] Appl. Phys. Lett. 2013, 102, 176101.

(4) Nadkarni G. S.; Shirodkar, V. S. Experiment and Theory for Switching in $\mathrm{Al} / \mathrm{V}_{2} \mathrm{O}_{5} / \mathrm{Al}$ Devices. Thin solid films 1983, 105, 115-129.

(5) Kang, M.; Kim, I.; Kim, S. W.; Ryu, J.-W.; Park, H. Y. Metal-Insulator Transition without Structural Phase Transition in $\mathrm{V}_{2} \mathrm{O}_{5}$ Film. Appl. Phys. Lett. 2011, 98, 131907-3.

(6) Blum, R. -P.; Niehus, H.; Hucho, C.; Fortrie, R.; Ganduglia-Pirovano, M. V.; Sauer, J.; Shaikhutdinov, S.; Freund, H.-J. Surface Metal-Insulator Transition on a Vanadium Pentoxide (001) Single Crystal. Phys. Rev. Lett. 2007, 9, 226103-4.

(7) Raible, I.; Burghard, M.; Schlecht, U.; Yasuda, A.; Vossmeyer, T. $\mathrm{V}_{2} \mathrm{O}_{5}$ Nanofibres: Novel Gas Sensors with Extremely High Sensitivity and Selectivity to Amines. Sens. Actuators B 2005, 106, 730-735.

(8) Dhayal Raj, A.; Pazhanivel, T.; Kumar, P. S.; Mangalaraj, D.; Nataraj, D.; Ponpandian, N. Self Assembled $\mathrm{V}_{2} \mathrm{O}_{5}$ Nanorods for Gas Sensors. Curr. Appl. Phys. 2010, 10, 531-537.

(9) Nishio, S.; Kakihana, M. Evidence for Visible Light Photochromism of $\mathrm{V}_{2} \mathrm{O}_{5}$. Chem. Mater. 2002, 14, 3730-3733. 
(10) Zuli, L.; Guojia, F.; Youqing, W.; Yandong, B. Laser-Induced Colouration of $\mathrm{V}_{2} \mathrm{O}_{5} . J$. Phys. D: Appl. Phys. 2000, 33, 2327-2332.

(11) Krishnakumar, S.; Menon, C. S. Optical and Electrical Properties of Vanadium Pentoxide Thin Films. phys. stat. sol. (a) 1996, 153, 439-444.

(12) Xie, S.; Iglesia, E.; Bell, A. T. Effects of Temperature on the Raman Spectra and Dispersed Oxides. J. Phys. Chem. B 2001, 105, 5144-5152.

(13) Enjalbert, R.; Galy, J. A Refinement of the Structure of $\mathrm{V}_{2} \mathrm{O}_{5}$. Acta Crystallogr., Sect. C: Cryst. Struct. Commun.1986, 42, 1467-1469.

(14) Lambrecht, W.; Djafari-Rouhani, B.; Vennik, J. Electronic Structure of Bulk and Surface Vanadyl Oxygen Vacancies in the Layer Compound $\mathrm{V}_{2} \mathrm{O}_{5}$. Surf. Sci. 1983, 126, 558-564.

(15) Eon, J. G.; Olier R.; Volta, J. C. Oxidative Dehydrogenation of Propane on $\gamma-\mathrm{Al}_{2} \mathrm{O}_{3}$ Supported Vanadium Oxides. J. Catal. 1994, 145, 318-326.

(16) Ramirez, R.; Casal, B.; Utrera, L.; Ruiz-Hitzky, E. Oxygen Reactivity in Vanadium Pentoxide: Electronic Structure and Infrared Spectroscopy Studies. J. Phys. Chem. 1990, 94, 8960-8965.

(17) Rubin Aita, C. Additional Comment on "Metal-Insulator Transition without Structural Phase Transition in $\mathrm{V}_{2} \mathrm{O}_{5}$ Film" [Appl. Phys. Lett. 98, 131907 (2011)]. Appl. Phys. Lett. 2014, 104, 176101-2.

(18) Wilhelmi, K. A.; Walterson, K. On the Crystal Structure of a New Vanadium Oxide, $\mathrm{V}_{4} \mathrm{O}_{9}$. Acta. Chem. Scand. 1970, 24, 3409-3411.

(19) Abello, L.; Husson, E.; Repelin, Y.; Lucazeau, G. Vibrational Spectra and Valence Force Field of Crystalline $\mathrm{V}_{2} \mathrm{O}_{5}$. Spectrochim. Acta, Part A: Mol. Spectrosc. 1983, 39, 641651. 
(20) Baddour-Hadjean, R.; Pereira-Ramos, J. P.; Navone, C.; Smirnov, M. Raman Microspectrometry Study of Electrochemical Lithium Intercalation into Sputtered Crystalline $\mathrm{V}_{2} \mathrm{O}_{5}$ Thin Films. Chem. Mater. 2008, 20, 1916-1923.

(21) Bachmann, H. G.; Ahmed, F. R.; Barnes, W. H. The Crystal Structure of Vanadium Pentoxide. Z. Kristallogr. 1961, 115, 110-131.

(22) Clauws, P.; Broeckx, J.; Vennik, J. Lattice Vibrations of $\mathrm{V}_{2} \mathrm{O}_{5}$. Calculation of Normal Vibrations in a Urey-Bradley Force Field. phys. stat. sol. (b) 1985, 131, 459-473.

(23) Chakrabarti, A.; Hermann, K.; Druzinic, R.; Witko, M.; Wagner, F.; Petersen, M. Geometric and Electronic Structure of Vanadium Pentoxide: A Density Functional Bulk and Surface Study. Phys. Rev. B 1999, 59, 10583-10590.

(24) Parker, J. C.; Lam, D. J.; Xu, Y.-N.; Ching, W. Y. Optical properties of vanadium pentoxide determined from ellipsometry and band-structure calculations. Phys. Rev. B 1990, 42, 5289-5293.

(25) Eyert V.; Höck, K.-H. Electronic Structure of $\mathrm{V}_{2} \mathrm{O}_{5}$ : Role of Octahedral Deformations. Phys. Rev. B 1998, 57, 12727-12737.

(26) Karakotsou, Ch.; Kalomiros, J. A.; Hanias, M. P.; Anagnostopoulos, A. N.; Spyridelis, J. Nonlinear Electrical Conductivity of $\mathrm{V}_{2} \mathrm{O}_{5}$ Single Crystals. Phys. Rev. B 1992, 45, $11627-$ 11631.

(27) Cocciantelli, J. M.; Gravereau, P.; Doumerc, J. P.; Pouchard, M.; Hagenmuller, P. On the Preparation and Characterization of a New Polymorph of $\mathrm{V}_{2} \mathrm{O}_{5}$. J. Solid State Chem. 1991, 93, 497-502.

(28) Ganduglia-Pirovano, M.; Sauer, J. Stability of Reduced $\mathrm{V}_{2} \mathrm{O}_{5}$ (001) Surfaces. Phys. Rev. B 2004, 70, 045422-13. 
(29) Sauer, J.; Dobler, J. Structure and Reactivity of $\mathrm{V}_{2} \mathrm{O}_{5}$ : Bulk Solid, Nanosized Clusters, Species Supported on Silica and Alumina, Cluster Cations and Anions. Dalton Trans. 2004, 3116-3121.

(30) Baddour-Hadjean, R.; Smirnov, M. B.; Kazimirov, V. Y.; Smirnov, K. S.; Pereira-Ramos, J.-P. The Raman Spectrum of the $\Gamma^{\prime}-\mathrm{V}_{2} \mathrm{O}_{5}$ Polymorph: A Combined Experimental and DFT Study. J. Raman Spectrosc. 2015, 46, 406-412.

(31) Lambrecht, W.; Djafari-Rouhani, B.; Vennik, J. On the Origin of the Split-Off Conduction Bands in $\mathrm{V}_{2} \mathrm{O}_{5}$. J. Phys. C: Solid State Phys. 1981, 14, 4785-4795.

(32) Lambrecht, W.; Djafari-Rouhani, B.; Vennik, J. Theoretical Study of the Vanadyl-Oxygen Vacancy in $\mathrm{V}_{2} \mathrm{O}_{5}$ : Tight-Binding Green Function Calculation, Optical Properties and Neutral Vacancy Ground-State Splitting. J. Phys. C: Solid State Phys. 1986, 19, 369-388.

(33) Khan, G. A.; Hogarth, C. A.; Electron Spin Resonance Studies of Evaporated $\mathrm{V}_{2} \mathrm{O}_{5}$ and Co-Evaporated $\mathrm{V}_{2} \mathrm{O}_{5} / \mathrm{B}_{2} \mathrm{O}_{3}$ Thin Films. J. Mater. Sci. 1991, 26, 2707-2710.

(34) Wu, Q.-H.; Thissen, A.; Jaegermann, W.; Liu, M. Photoelectron Spectroscopy Study of Oxygen Vacancy on Vanadium Oxides Surface. Appl. Surf. Sci. 2004, 236, 473-478. 


\section{Supplementary information}

\section{Role of Vanadyl Oxygen in Understanding Metallic Behavior of $\mathrm{V}_{2} \mathrm{O}_{5}(001)$ Nanorods \\ Raktima Basu, ${ }^{*}$ Arun K. Prasad, Sandip Dhara, ${ }^{*}$ and A. Das}

Nanomaterials and Sensors Section, Surface and Nanoscience Division, Indira Gandhi Centre for Atomic Research, Homi Bhabha National Institute, Kalpakkam-603 102, India

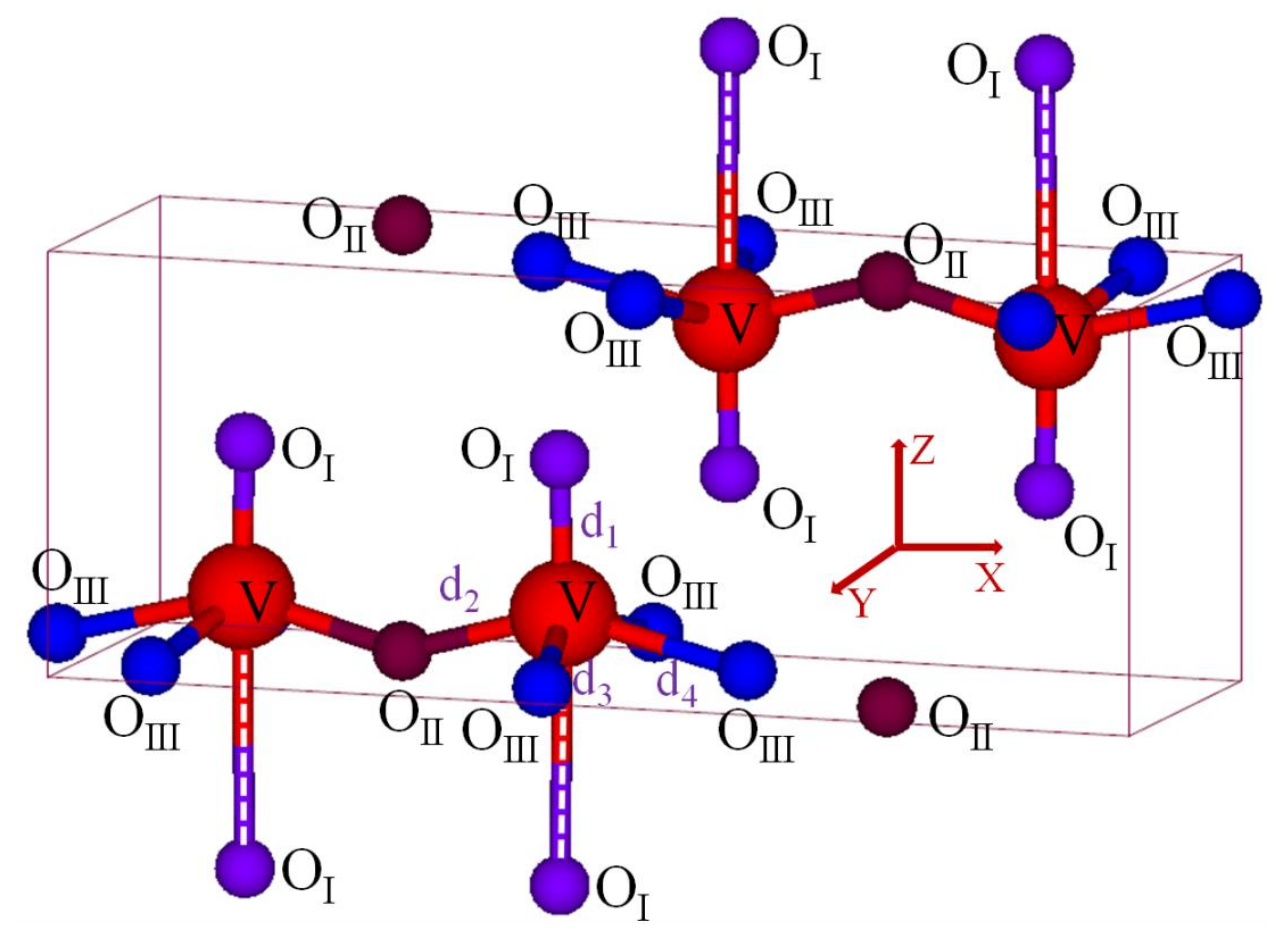

Figure S1. Schematic diagram of $\mathrm{V}_{2} \mathrm{O}_{5}$ unit cell

Figure $\mathrm{S} 1$ shows the schematic diagram of $\mathrm{V}_{2} \mathrm{O}_{5}$ unit cell. Orthorhombic $\mathrm{V}_{2} \mathrm{O}_{5}$ crystallizes in a layered structure perpendicular to the $Z$-axis consisting of $\mathrm{VO}_{5}$ pyramids sharing their vertices and corners. There are three non-equivalent oxygen atoms in each unit cell (denoted as $O_{l}, O_{\| l}$, and $O_{I I I}$ ). $O_{l}$ is the terminal (vanadyl) oxygen with two different bond lengths. One of them is strong and short $\mathrm{V}-\mathrm{O}$, bond with length $1.577 \AA\left(d_{1}\right)$. Another one is large and weak Van der Waals type, which connects the two adjacent layers in the $\mathrm{V}_{2} \mathrm{O}_{5}$ structure, with a bond length of $2.793 \AA$ (showed by dotted white lines). Both of these vanadyl oxygen atoms orient almost along the $c$-axis. The two fold coordinated bridging oxygen $\left(\mathrm{O}_{\|}\right)$ 
connects two adjacent $V$ atoms with $V$ - $O_{\text {II }}$ bond length of $1.78 \AA\left(d_{2}\right)$. The ladder shaped $\mathrm{O}_{\text {III }}$ atoms are the three-fold coordinated oxygen with three different V-O III bond lengths of $1.88\left(d_{3}\right), 1.88\left(d_{3}\right)$, and $2.02 \AA\left(d_{4}\right)[$ Ref: 13 in the main text].

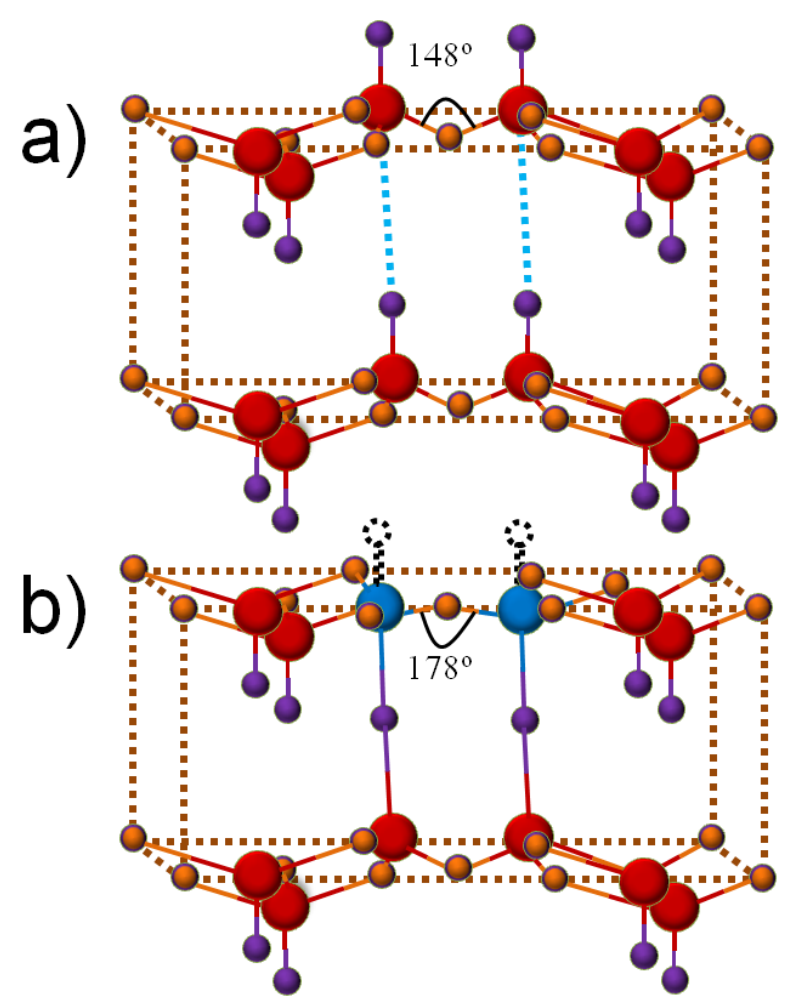

Figure S2. Schematic diagram of $\mathrm{V}_{2} \mathrm{O}_{5}$ unit cell (a) below and (b) above transition temperature

Figure S2 shows the structure of $\mathrm{V}_{2} \mathrm{O}_{5}$ unit cell below (Figure S2 (a)) and above (Figure S2 (b)) the transition temperature. If one of the vanadyl oxygen atoms are removed from the surface, the $V$ atom in its near vicinity projects inward for relaxation and the next right vanadyl oxygen relax upward to make a stiffer interlayer bond with increased bond length (1.78 $\AA$ ). Moreover, the $\mathrm{V}-\mathrm{O}_{\mathrm{II}} \mathrm{V}$ bond angle is also reported to increase to $178^{\circ}$ leading to almost a linear bond. [Ref: 28 in the main text]. 